\title{
Sons and Daughters' Perception of Parents as a Couple: Distinguishing Characteristics of a Measurement Model
}

\author{
A Percepção dos Filhos sobre a Conjugalidade dos Pais: Características \\ Distintas de um Modelo de Medida
}

\author{
Cilio Ziviani*, Terezinha Féres-Carneiro, \& Andrea Seixas Magalhães \\ Pontificia Universidade Católica do Rio de Janeiro, Rio de Janeiro, Brasil
}

\begin{abstract}
Perceptions and memories that youths may have of their parents' marital relationship were addressed by a self-report questionnaire, composed by 26 Likert scale items which were taken to constitute the "Perception of Parents as a Couple" instrument. Answers from 1,612 male and female youths produced a matrix of non-negative correlations. The sample was randomly split into calibrating and validating subsamples of 806 people each. Exploratory factor and principal component analyses present a circular plot of loading $\mathrm{S}$ after the first and second extractions. In the latter, pairs of similar magnitude, but of opposing signs, not only convey theoretical meaning, but also entail an order - Guttman's circular law of order. A specification search, through a confirmatory factor analysis, performed under a measurement model presenting three pairs of opposing-signs and cross-loaded variables, generated a downward chi-square value for each indicated parameter respecification. Following that ordered list top-down, ten other items were specified to cross-load in the model. Once tested, running the validating subsample data, satisfactory fit indices were obtained. We propose the Möbius strip as a functional analogue to model this kind of circular ordering. Finally, we nominate two theoretical orientations for further research on the explanation of results - the generational psychic transmission reviewed in the introduction contrasted to the cognitive unconscious theory. Keywords: Parents' marital relationship; Circumplex structure; Möbius strip; Confirmatory factor analysis.
\end{abstract}

\begin{abstract}
Resumo
Percepções e memórias que os jovens tenham das relações conjugais de seus pais foram investigadas por um questionário auto-aplicável, no qual 26 itens tipo Likert constituíram o instrumento sobre a Percepção dos Pais na Conjugalidade. Respostas de 1.612 jovens adultos produziram uma matriz de correlações nãonegativas. A amostra foi dividida aleatoriamente em subamostras de calibração e de validação, com 806 pessoas cada. Análises exploratórias fatoriais e de componentes principais apresentam um gráfico de cargas de forma circular, após a primeira e a segunda extração. Nesta última, pares de magnitude similar, mas de sinais opostos, não apenas expressam significado teórico, mas acarretam uma ordem - a lei da ordem circular de Guttman. Uma busca de especificação, por meio de análise fatorial confirmatória executada sob um modelo de medida apresentando três pares de variáveis de carga cruzada e sinais opostos, apresentou um valor de qui-quadrado, classificado do maior para o menor, para cada re-especificação de parâmetro indicada. Seguindo esta lista de cima para baixo, mais dez itens foram especificados para cruzamento de carga no modelo. Uma vez testado, processando os dados da subamostra de validação, resultam índices de ajuste satisfatórios. Propomos a fita de Möbius como um análogo funcional para modelar esse tipo de ordenação circular. Finalmente, nomeamos duas orientações teóricas para a pesquisa posterior acerca da explanação dos resultados - a transmissão psíquica geracional revista na introdução, contrastada com a teoria do inconsciente cognitivo.

Palavras-chave: Conjugalidade dos pais; Estrutura circumplexa; Fita de Möbius; Análise fatorial confirmatória.
\end{abstract}

One major assumption held by the theoretical standpoint of generational psychic transmission is that psychological processes between parents are transmitted to sons and daughters. Our underlying assumption is that there is a
This research was supported by grants from the Brazilian agencies CNPq and FAPERJ which included scholarships to the research assistant collaborators Aline Vieira de Souza, Laura Marques Rizzaro, Luciana Janeiro Silva, Mariana Reis Barcellos, Vanessa Augusta de Souza, and to the technical collaboration of Rebeca Nonato as well. In addition, authors wish to acknowledge the support of Prof. Orestes Diniz Neto, from the Department of Psychology of the Federal University of Minas Gerais, and Prof. Virgílio Gomes do Nascimento, from the Psychology Program at Sociedade Educacional Fluminense, for collecting data in Belo Horizonte and Baixada Fluminense, respectively, and also the assistance of Isabel Elia Ziviani, designer, for the graphical work with figures.

"Address: Department of Psychology, Pontifícia Universidade Católica do Rio de Janeiro, Rua Marquês de São Vicente, 225, Gávea, Rio de Janeiro, Brasil, CEP 22453900. E-mail: cilio.ziviani@gmail.com. Data sets referred in the article are available upon request. 
relationship between parents' marital relations and the concepts, motivations, myths and expectations that sons and daughters have about the marital link. Knowing about this relationship helps understanding sons and daughters' current position about the role of marriage in their lives.

Thus, the influence parents' marital relations may exert in the consideration of the marital link in the life project of not yet married young adults provides the framework for the presentation of a scale that asks sons and daughters about their parents' marital relations. The interrelationships among the scale item responses produced a resulting covariance matrix with a variety of unexpected characteristics. Some of these characteristics - positive manifold, circumplex, meaningful two-factor cross-loading of items - are fully addressed in the present article. They are finally tested, using an independent second sample in a confirmatory factor analysis measurement model.

The theoretical concept of generational psychic transmission goes back to the Freudian notion that the newborn, as a subject, is symbolically inserted in a chain in which he or she is a link, and that he or she serves even against one will (Kaës, 1993/2003). According to Freud (1914/ $1999 b$ ), the person does carry on a twofold existence, one to serve his or her own purposes (sein Selbstzweck), and the other constituting a link in a chain (als Glied in einer Kette), in which the person serves against his or her will, or at least involuntarily. What follows is the tension between serving one's own purposes and being a link, beneficiary, servant, and heir of a generational chain for it defines his or her position as subject of a group, i.e., his or her family.

When investigating the family, we are permanently confronted with different faces of the generational psychic transmission. From the psychic point of view, the family has the central challenge of promoting the individuation of its members. The accomplishment of this task implies the agency of the subject to the place which he or she belongs in the generational chain. The family that psychically nourishes the baby subject since birth, and even before its gestation, preparing a symbolic place to receive it, wishing it, is the same family that has the mission of launching it to the world to germinate its history, its legacy.

Investigations on the family have provided important subsidies to understand psychic transmission. In contemporary society there is a variety of relationship arrangements, presenting a raising number of separations and remarriages. The love link presents itself increasingly unstable, of short duration and with plenty of uncertainties regarding its development. In the current society characterized by the instantaneous and the disposable, love relationships offer less emotional refuge, frequently rendering into helplessness.

Even so, the family continues to exert a social-affective function, yet representing a refuge against the so-called "liquid modernity" (Bauman, 2003). On the one hand, we face the fluidity and discontinuity of the marital link; on the other hand, there is the difficulty that single adult sons and daughters have to break off their financial and emotional-affective dependency on their families of origin, in order to inaugurate a new and necessary condition as autonomous adults. There are in the literature reports of an increasing number of sons and daughters, around thirty years of age, living with their parents, with lesser expectations of their marrying possibilities or of raising their own families (Enriques, Féres-Carneiro, \& Magalhães, 2006; Ramos, 2003).

This is the overall theoretical framework within which the present research was first conceived. An instrument that would be sensible enough to detect meaningful signs of how subjects recollect their parents' marital relations could be useful. First, in the research setting, to detect how the perception of parents as a couple would influence how sons and daughters currently conceive the marital link in their lives. Second, the instrument would be useful in the clinical endeavor of helping people to better cope with their psychic inheritance.

This instrument, devised as a five-category Likert-type sixty-item questionnaire, was elaborated under two major sources of influence: the ENRICH Marital Inventory, and the Family Background Questionnaire (FBQ). The first was designed as a multidimensional inventory, which assesses dimensions of marital relationships, as its acronym indicates (Evaluating and Nurturing Relationship Issues, Communication, and Happiness: ENRICH). Both its validity study (Fowers \& Olson, 1989) and its major application in a sample of 6,267 couples (Olson \& Fowers, 1993) were used as a source of inspiration for writing item content. The second instrument - the Family Background Questionnaire ([FBQ], Melchert \& Sayger, 1998), addresses the characteristics of the family of origin and was developed following a thorough review of the available instruments for assessing family history (Melchert, 1998) - under the proviso that family of origin instruments assess family of origin memories, but not the veridicality of the memories reported.

As Melchert and Sayger (1998) insist, to achieve a full understanding of the validity of family of origin instruments, two perspectives may be applied, a veridical and a phenomenological. Although family of origin memory veridicality may be important in a forensic dispute, one cannot infer that experiences reported as family of origin memories actually took place, for there are factors that may result in inaccurate perception and recall. Concluding, Melchert and Sayger (1998) posit that objectively accurate and meaningful criteria for establishing the veridicality of all family of origin memories do not exist.

In line with the FBQ, our present Perception of Parents as a Couple (PPC) scale, as part of an overall questionnaire about parents marital relationships, is situated into Melchert and Sayger's (1998) phenomenological perspective. Our results from multivariate analyses support the theoretical foundation for the measurement model, but not necessarily the veridicality of the memories reported as responses to the scale items. 


\section{Strategy of Analysis}

The sample of 1,612 participants was divided into two halves using a computerized random procedure. The first half was the subsample for the exploratory, model generating phase of analysis. The second half was the subsample used to finally test the model indicated by the exploratory procedures developed in the first phase. "Model generating" is an expression used by Jöreskog (1993) when discussing issues related to the translation of a theory to a statistical model. Inspiration for our strategy of analysis comes from this author.

Under this methodological framework, twenty-six items comprising the Perception of Parents as a Couple scale were submitted to an Exploratory Factor Analysis (EFA), after a Principal Components Analysis (PCA), in order to investigate its dimensionality and factorial structure. The third step in the exploratory phase was the tentative testing of the preliminary exploratory results, using a Confirmatory Factor Analysis (CFA) measurement model. A considered model, initially proposed, may not fit the data set well. Thus, the question is how to modify the model seeking a better fit to the data at hand. The answer to this question is to be found in the so-called specification search process, in which changes in chisquare - using Lagrange Multiplier test statistics - indicate parts of the model that, if altered, would improve the fitting of the model to the data.

Is the result, then, the "best" model? No, absolutely not. Specification search by itself does not guarantee model quality, because its results could have been reached by "capitalizing on chance". Reasonable models generated by means of that kind of model specification process should be cross-validated on independent data. This is the role of the second half of our sample: to serve as a validation subsample in the final testing of the "best" model arrived at the first half using the calibration subsample.

\section{Method}

\section{Participants}

The sample consisted of 1,612 young adults between 18 and 29 years of age $(M=22.23, S D=3.25)$, both male $(42 \%, N=681)$ and female $(58 \%, N=931)$, from which $1,424(88 \%)$ reported being single. For most $(84 \%, N=$ 1.349 ), the parents were the reference couple for answering the questionnaire. Most of the participants were recruited in the city of Rio de Janeiro $(27 \%, N=437)$ and its surroundings $(62 \%, N=993)$; the other persons were recruited in the city of Belo Horizonte $(11 \%, N=182)$. Most $(65 \%, N=1.049)$ were attending college or had already reached a higher educational level; more than half $(59 \%, N=949)$ reported belonging to middle-class, uppermiddle-class or higher. Finally, a minority reported living out of their parents' home $(20 \%, N=328)$, whereas most reported living with both parents $(53 \%, N=862)$, with the mother $(22 \%, N=351)$, or with the father $(4 \%, N=$ 61). Ten people did not answer this question.

\section{Instrument}

The 26-item Perception of Parents as a Couple (PPC) scale is part of a 60 -item questionnaire on father and mother marital relations as seen by their sons and daughters. The present 26 items address both parents; they do not distinguish between father and mother, as done by other items in the overall questionnaire. The Likert five categories are never, rarely, sometimes, generally, and always. The remaining items are in different formats. For instance, 28 of them refer, actually, to 14 pairs of same-item, but referred to a different parent (one for the mother, and the other for the father). The remaining items have an intermediate category for the situations where this is the best kind of answer.

The research project was approved by the university Ethical Committee. The questionnaire, as well as a biographical form, was first applied to a pilot casual sample of 278 people recruited in undergraduate and graduate classes from ten different universities in the city of Rio de Janeiro. Among them, 251 young adults then met the research conditions of being single, middle and uppermiddle-class, and between 19 and 30 years of age. A number of items, none of them from the present 26-item PPC scale, were modified after thorough psychometric evaluation. In its preliminary form, the overall scale presented high reliability (Cronbach's alpha, .96) for 56 items taken together (four items were left out of the analysis). The preliminary study also interviewed 14 people who had responded the questionnaire, with the main goal of knowing how they conceived the marital link, and how the prospect of marrying was considered in their life project (Féres-Carneiro, Seixas, \& Ziviani, 2006).

These investigations contributed to improve the final form of the overall questionnaire, which was then applied to 1,855 people. Those out of the 18 to 29 years of age range were separated, and the result refers to the present sample of 1.612 persons - divided, for the present study, into halves of 806 persons each, using a computer program "random" sampling of cases procedure (SPSS, 2002, base 11). As previously mentioned, the first half was used in the present study as a calibration subsample; the other half, as a testing for validation subsample. In the calibrating subsample, there were 39 cases $(4.84 \%)$ with a missing response in at least one of the 26 items, and in the testing subsample there were 50 cases $(5.46 \%)$. After considering Graham (2009), and after a close scrutiny of the data set using a missing value analysis procedure (SPSS), no systematic source of variation was found. Thus, we decided to adopt listwise deletion, i.e., cases that have missing values for any of the 26 items were omitted in the analyses. 


\section{Results and Discussion}

Reliability of the PPC scale on both subsamples is alfa $=.96$ (the same .96 observed in the pilot study, and reported by Melchert and Sayger in 1998). Before proceeding to the results of multivariate analyses, we comment on differences between exploratory factor analysis (EFA) and principal component analysis (PCA) that bear directly on our results. "Principal components have the special property that the vectors of loadings are orthogonal and the component scores are uncorrelated ... because of the presence of orthogonal rotations at the heart of the algorithm for simple components" (Jolliffe, 2004, p. 291). As such, one can view the effect of carrying a PCA as a rigid rotation of the original coordinate axes. In effect, according to Raykov and Marcoulides (2008), performing a PCA precludes the need for rotation of resulting principal components. In short, while EFA produce factors, PCA produce components that are independent, and component scores that are uncorrelated.

\section{Exploratory Procedure}

Table 1 presents loadings from both an EFA and a PCA. Principal Axis Factoring (SPSS) was the method used for EFA. Estimates of communality, instead of 1's as in PCA, are in the diagonal of the correlation matrix, and only the variance that each variable shares with other variables in the analysis at hand is factor analyzed.

All columns of Table 1 are sorted in descending order of the statistics - communalities, factor loadings, and component loadings. The amount of variance accounted for by each factor or component - its eigenvalue - is given by each column sum of squared loadings (Tabachnick \& Fidell, 2007). For example, the sum of squares (SS) at the bottom of the table for $\mathrm{C} 1$ amounts to 13.22, and for $\mathrm{C} 2$ to 2.08. Since PCA considers all the variance (equal to 26 , the number of variables), $\mathrm{C} 1$ accounts for $50.85 \%$ $(13.22 / 26=.5085)$ of the variance, while $\mathrm{C} 2$ accounts for $8 \%(2.08 / 26=.08)$. F1 and F2 account for less than that, since PAF analyzes common variance only.

There are the high loadings on unrotated F1, as well as on unrotated $\mathrm{C} 1$. Loadings are correlations between the item and the factor or component. The only item with a correlation lower than .50 is 54 break, with .48 on F1, and .49 on $\mathrm{C} 1$. This result suggests that the scale is unidimentional. If this is the case, what might the second factor mean? EFA presents nine items with either positive or negative loadings higher than .30, and lower than -.30. Considerations on statistical power are offered by Hair, Black, Babin, Anderson and Tatham (2006) as a guideline for identifying significant factor loadings. They based their proposition on sample size, under the stated objective of obtaining a power level of 80 percent, the use of a .05 significance level, and standard errors twice as higher as those of conventional correlation coefficients. Under these conditions, a factor loading of . 30 needs, for significance, a sample size of $N=350$ persons (for a .40 factor loading, 200 persons are needed; .50, 120; .60, 85; and for .70, 60 persons). Thus, at $N=767$, our calibrating subsample is more than twice the minimum size required for significance of a .30 loading.

\section{Exploratory Factor Analysis}

As far as unrotated loadings are concerned, be them from EFA or PCA, we should consider that all items belong to the first dimension. Furthermore, this overall result is one indication that the scale is unidimensional, i.e., it measures only one construct. However, there is a second factor, and certainly there is a second component, which is orthogonal to the first, i.e., independent on the first. Although the same cannot be said of EFA, since it takes into account only the variance items have in common (their communalities), the overall result is practically equivalent - except for the Varimax rotation.

The Varimax orthogonal rotation does achieve a simple structure, as we can see in Table 1. The simple structure presents two factors. Let us keep in F1 the eighteen items from 30 caress down to 05 share. This proceeding coincides to the point, in F2, that items from 44 flexible down to 42 kiss start presenting lower loadings of .29 or less. However, does it make sense, from a psychological perspective, to keep in the same dimension such opposing items as 29 fight (a loading of .77 ) side by side with 60 happy (a loading of .57)? We believe it does not.

\section{Principal Components and the Circumplex}

Thus, we decided to keep the PCA results and explore the fact that $\mathrm{C} 1$ is orthogonal to $\mathrm{C} 2$, i.e., they are independent. $\mathrm{C} 1$ and $\mathrm{C} 2$ loadings are again depicted in Figure 1, organized to show distinguishing characteristics of the measurement model data not easily detected by the analyses conducted so far of the first two components, the first component on the $\mathrm{X}$-axis and the second on the Y-axis. The scatter of data points, forming a close-to half circle, suggests a circumplex structure. "Circumplex" is the contraction of the words circular continuum of complexity. Guttman (1954/1955) coined this term when arguing that some human characteristics differing in kind should have an order among them, but not a simple order of complexity, in which there is a ranking from highest to lowest. Then, Guttman asks himself: would it be possible to have an ordering without a head and foot to it? And promptly provided the answer:

Yes, quite simply, by having it circular. Then the order has neither beginning nor end. All variables have an equal rank, but still there is a law of neighboring that holds. A system of variables which has a circular law of order is a circumplex $(1954 / 1955$, p. 325).

Concluding, Guttman asserts that "the simplex and the circumplex seem to be the first examples of structures for factor analysis with a law of order which makes the role of principal components unmistakably important" (1954/1955, p. 348). 


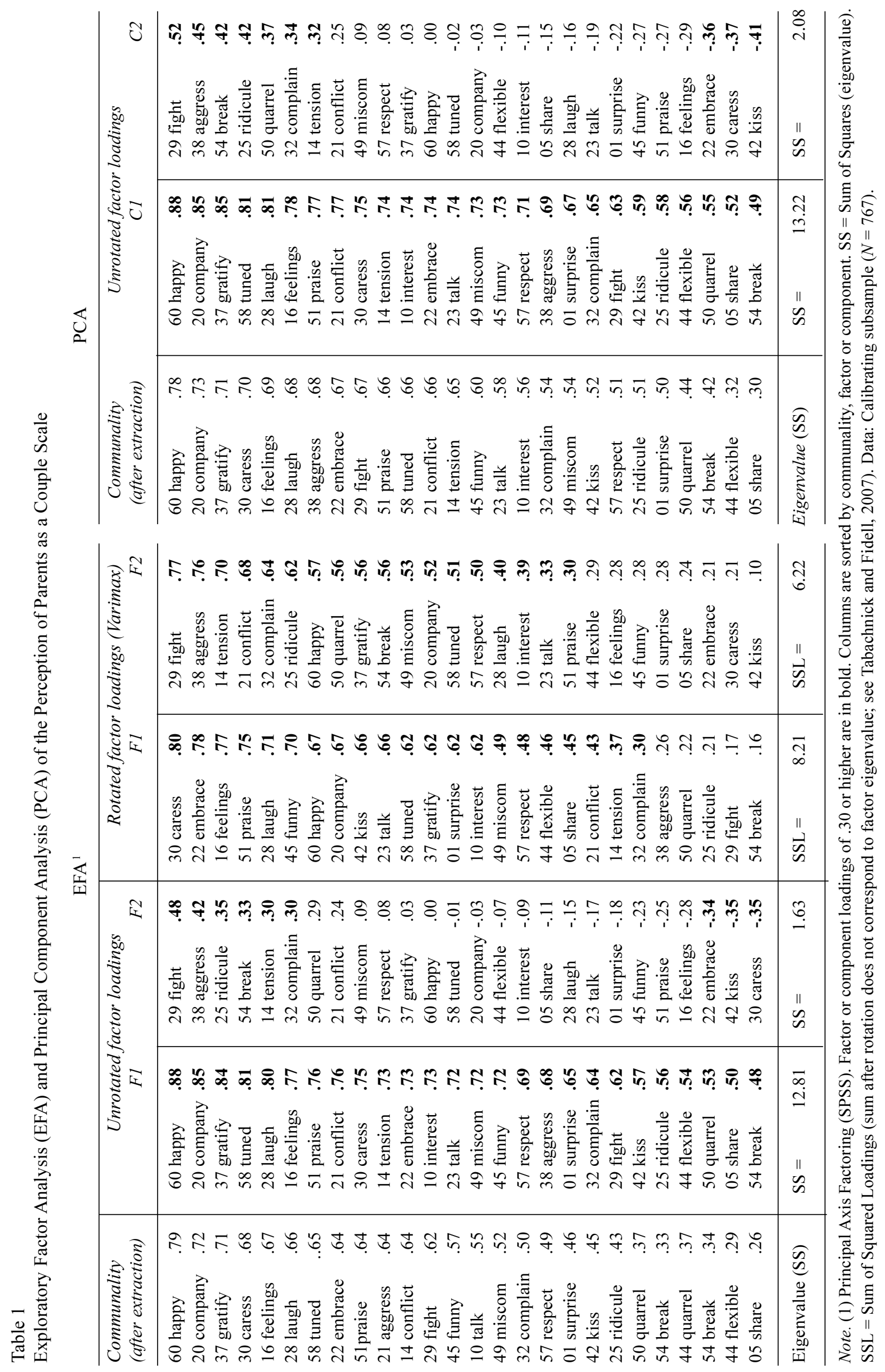




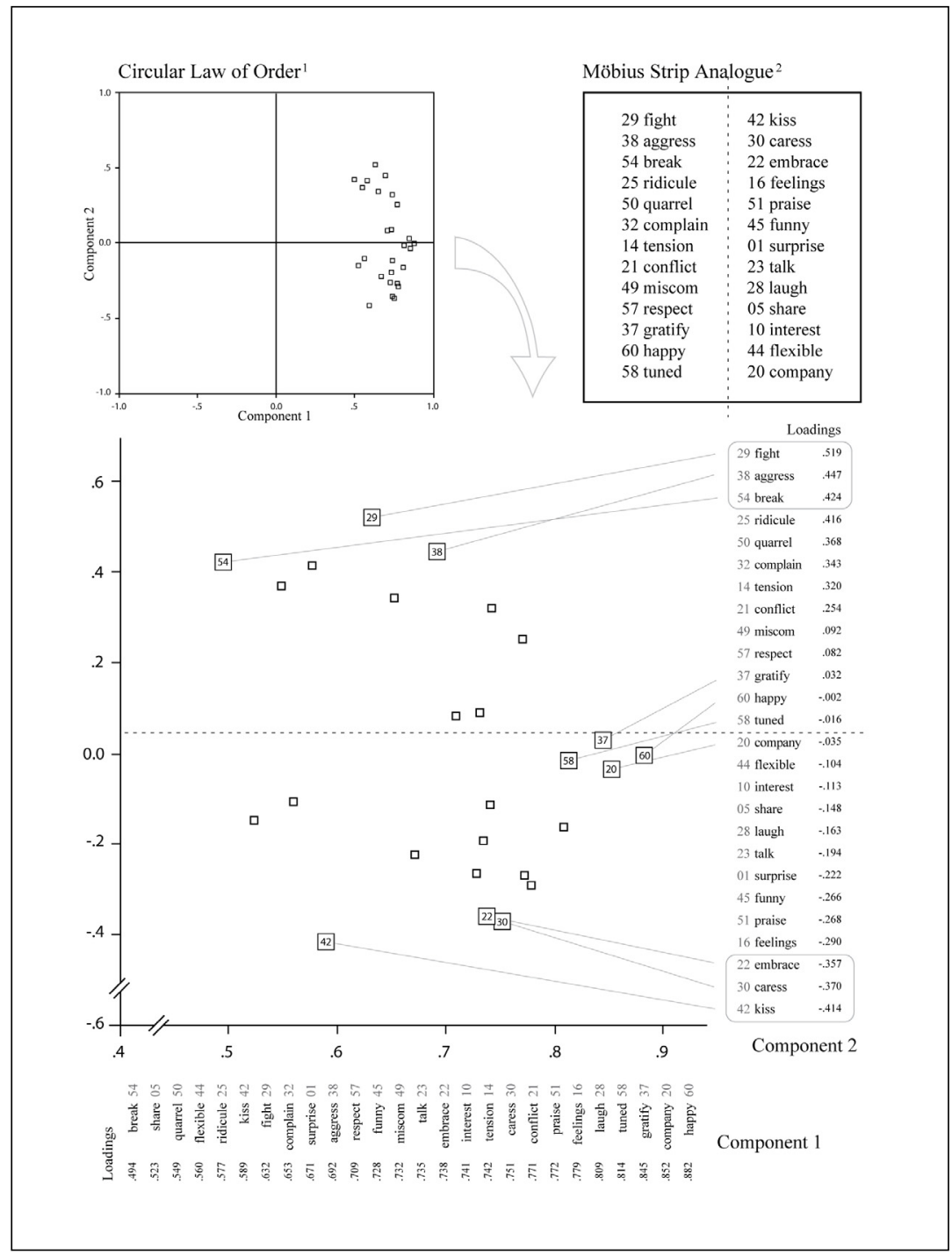

Figure 1. Plot of Component 1 and Component 2 Item Loadings of the PPC Scale Note. (1) Or "law of neighboring": Guttman (1954/1955). (2) Möbius (1886). The curvilinear plot illustrates the polarity between opposing elements inherent in the circumplex model (Plutchik, 1997).

Turning to Figure 1 again, one can see the items written sideways along the horizontal axis, positioned from low to high loadings on the first component. Similarly, on the vertical, at the right side, from top to bottom, one can see, from high to low loadings, the items on the second component. The first is 29 fight (loading of .519); the last, 42 kiss (loading of -.414). The cross-loading of items can be observed all over Figure 1.

Moreover, the order of the loadings in Component 1 does not make sense regarding meaningful item neighborhoods, while in Component 2 it does - items relating to affect are at the extremes, and indifferent items at the middle. In Component 2, there is a discernible semantic affinity among the items, turning the order amenable to theoretical interpretation. The existence of a such an order is postulated by Guttman (1954/1955) to serve as a criterion for recognizing a circumplex. For if one variable is chosen to be a focus, the correlation of this variable with both of its two nearest neighbors should be the highest of the set.

Appendix A presents the matrix of correlations among the 26 variables comprising our measurement model. Variables are in ascending order of item number. Nine variables are inside boxes (with capitalized letters for the item names). Three of them are at the upper extreme of the order of variables on the vertical axis of Figure 1 (FIGHT, AGGRESS, BREAK), three are at the lower extreme (KISS, CARESS, EMBRACE), and finally, the remaining three are in the middle of the scale (TUNED, HAPPY, GRATIFY). For instance, taking HAPPY as an example: its highest correlation is 808 (with GRATIFY), and its second highest correlation is .783 (with TUNED).

Looking back to Figure 1, one can see that both GRATIFY and TUNED are HAPPY's "next door" 
neighbors. In addition, the higher correlation (.808) refers to the neighbor above (GRATIFY), whereas the lower correlation refers to the neighbor below (TUNED), thus preserving the circular order. Among those nine variables, similar conditions occur. This empirical result accounts for a circular order that has neither beginning nor end, as in Guttman's circumplex.

Figure 1 also features the Möbius Strip Analogue box. The order of the items inside the box reflects the order of the loadings for Component 2. The column on the left side of the box features item 29 fight at the top, down to item 58 tuned. The column on the right side of the box features items 42 kiss at the top, down to 20 company. That column is reversed (i.e., reflected from the horizontal dotted line). We thus preserve the convergence of item meaning, going from an emotionally meaningful polarization of high-loading affect items, to a meaningless gathering of close-to-zero-loading emotionally indifferent items. Imagine, first, cutting the box with a pair of scissors and then folding the paper at the dotted line. If the item fight is up front, kiss is on the back; if caress is up front, aggress is on the back; and so forth. Now we have a strip that we can glue the ends together twisting one of the ends 180 degrees. When doing so, kiss will be neighbor to tuned, and fight neighbor to company. And there we have the items in a reversing circular law of order, in a nonorientable surface, that is, in a Möbius (1886) strip.

\section{Confirmatory Procedure}

Now the elements are at hand to investigate differences in covariance, to test measurement models in confirmatory factor analyses (CFA). Up to this point, we had a set of variables and we wanted to know how many factors or components were needed to account for the correlations among them, and what they were measuring. Contrasting to the exploratory phase, in CFA we start by defining the latent variables we would like to measure. As Jöreskog (2007) explains, with CFA no eigenvalues and eigenvectors are involved, the solution is obtained in one step, and no factor rotation is needed. CFA shifts the focus from EFA's factor extraction and rotation to the problem of testing a specified model.

Figure 2 presents a confirmatory factor analysis (CFA) for Measurement Model B (MMB). MMB was run by EQS (Bentler, 2006) using the calibrating sample data $(N=767)$. MMB replicates exactly the higher and lower portions of the classification of item loadings on Component 2 in Figure 1. The three highest loadings are 29 fight, 38 aggress, and 54 break, reading them top-down. By their position in the amplified plot of Component 1 and Component 2 loadings, we can see that these items load relatively low on Component 1 (.632, .692, and .494, respectively), as can be seen along the horizontal axis. These items are seen as reflected on the lowest three items on Component 2, at the bottom of the vertical column showing Component 2 loadings: 42 kiss, 30 caress, and 22 embrace, reading them bottom-up.

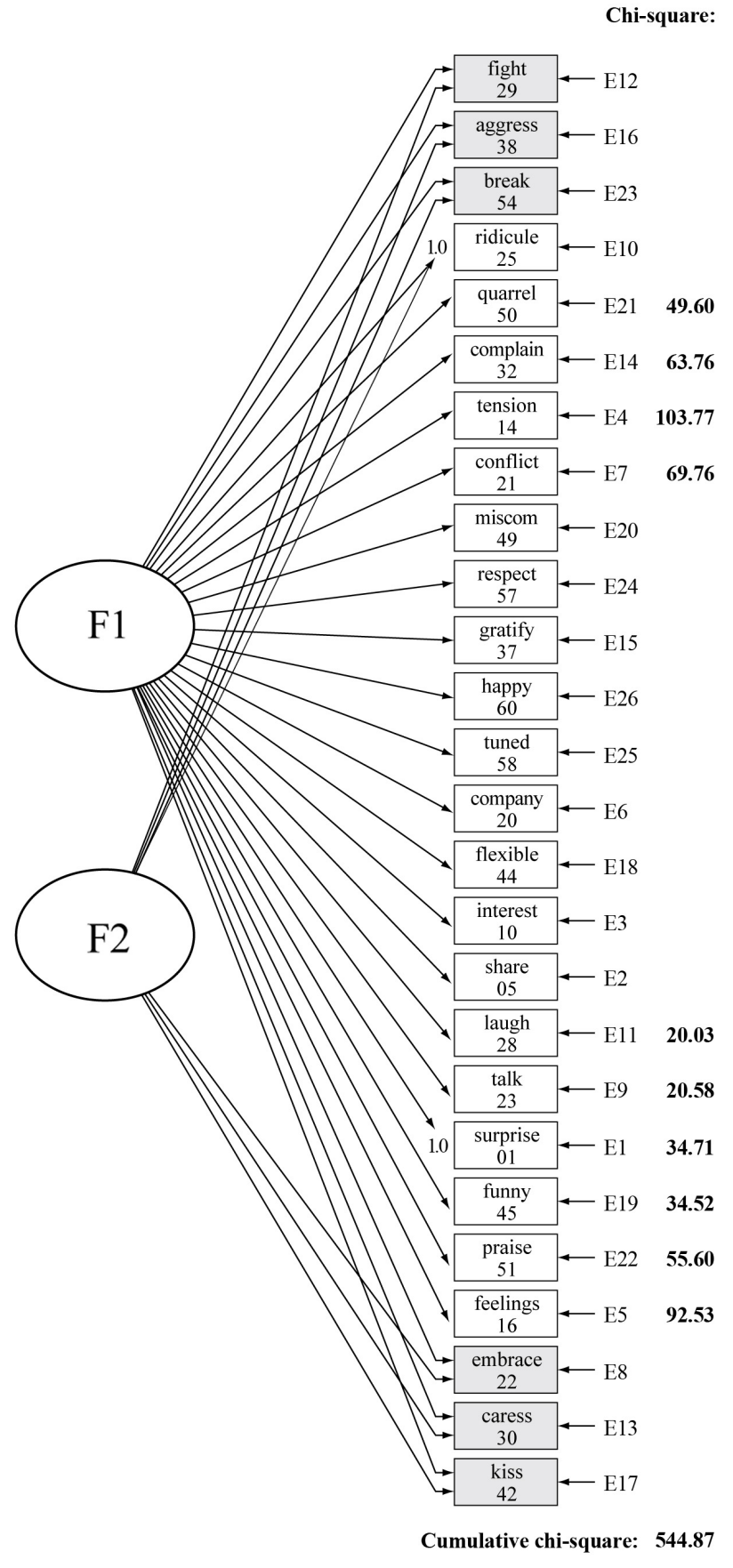

Figure 2. Confirmatory Factor Analysis (CFA) Measurement Model B

Note. Confirmatory factor analysis run by EQS (Bentler, 2006) on calibrating subsample $(N=767)$. Measurement indicator weights fixed at 1.0 by EQS (with program notation between parentheses): surprise $01(1 \mathrm{~F} 1+\mathrm{E} 1)$ and ridicule $25(1 \mathrm{~F} 2+\mathrm{F} 1+\mathrm{E} 10)$. Comparative Fit Index, CFI $=.899$. Root Mean Square Error of Approximation, RMSEA $=.073,90 \%$ Confidence Interval [.069, .076]. Chi-square values refer to specification search results.

Also in Figure 1, as we continue to read the items topdown and bottom-up, a pair at a time, we come to the dotted line dividing the highest loading items from the lowest (or the other way around, from the lowest to the highest). Around that dotted line are the items loading close to zero on Component 2. For instance, going bottom- 
Ziviani, C., Féres-Carneiro, T. \& Magalhães, A. S. (2011). Sons and Daughters' Perception of Parents as a Couple: Distinguishing Characteristics of a Measurement Model.

up, items from 20 company (loading or correlation with Component 2, -.035) through 37 gratify (loading or correlation with Component $2, .032$ ), would practically be eliminated, because whatever scores persons have on these items would be multiplied by these close-to-zero coefficients.

Table 2

Goodness of Fit Statistics and Specification Search for Confirmatory Factor Analysis (CFA) Measurement Models (Model A, Model B, and Model C)

A) Goodness of fit statistics for the calibrating subsample, $N=767$

\begin{tabular}{lcccccccccc}
\cline { 2 - 10 } $\begin{array}{l}\text { Measurement } \\
\text { Model }\end{array}$ & \multicolumn{4}{c}{ Method=Maximum Likelihood } & \multicolumn{3}{c}{ Method $=$ Robust } \\
\cline { 2 - 11 } & Chi-square & $d f$ & CFI & SRMR & RMSEA & $90 \%$ CI & CFI & RMSEA & $90 \%$ CI \\
\hline One-factor, Model A & 2563.28 & 299 & .838 & .067 & .099 & {$[.096, .103]$} & .861 & .084 & {$[.081, .088]$} \\
Two-factor, Model B & 1950.93 & 293 & .881 & .061 & .086 & {$[.082, .090]$} & .899 & .073 & {$[.069, .076]$} \\
Two-factor, Model C & 1251.15 & 282 & .931 & .037 & .067 & {$[.063, .071]$} & .942 & .056 & {$[.052, .060]$} \\
\hline
\end{tabular}

B) Goodness of fit statistics for the testing subsample, $N=762$

\begin{tabular}{lcccccccccc}
\cline { 2 - 9 } $\begin{array}{l}\text { Measurement } \\
\text { Model }\end{array}$ & \multicolumn{4}{c}{ Method $=$ Maximum Likelihood } & \multicolumn{3}{c}{ Method = Robust } \\
\cline { 2 - 10 } & Chi-square & $d f$ & CFI & SRMR & RMSEA & $90 \%$ CI & CFI & RMSEA & $90 \%$ CI \\
\hline Two-factor, Model C & 1234.22 & 282 & .935 & .033 & .067 & {$[.063, .070]$} & .947 & .057 & {$[.053, .060]$} \\
\hline
\end{tabular}

C) Multivariate Lagrange Multiplier (LM) test for adding parameters

Specification search for Model B fit improvement

\begin{tabular}{lrcccc}
\hline & \multicolumn{2}{c}{ Cumulative multivariate statistics } & \multicolumn{2}{c}{ Increment } \\
\cline { 2 - 6 } Step & Parameter & Chi-square & $d f$ & Chi-square & $d f$ \\
\cline { 2 - 5 } 1 & 14 tension, *F2 & 103.77 & 1 & 103.77 & 293 \\
2 & 16 feelings, *F2 & 196.30 & 2 & 92.53 & 292 \\
3 & 21 conflict, *F2 & 266.06 & 3 & 69.76 & 29 \\
4 & 32 complain, *F2 & 329.82 & 4 & 63.76 & 290 \\
5 & 51 praise, *F2 & 385.43 & 5 & 55.60 & 288 \\
6 & 50 quarrel, *F2 & 435.03 & 6 & 49.60 & 287 \\
7 & 01 surprise, *F2 & 469.74 & 7 & 34.71 & 286 \\
8 & 45 funny, *F2 & 504.26 & 8 & 34.52 & 285 \\
9 & 28 laugh, *F2 & 524.29 & 9 & 20.03 & 284 \\
10 & 23 talk, *F2 & 544.87 & 10 & 20.58 & 282 \\
11 & F2, F1 & 558.86 & 11 & 13.99 & 11.06 \\
12 & 57 respect, F2 & 569.92 & 12 & &
\end{tabular}

Specification search for Model C fit improvement

\begin{tabular}{lccccc}
\hline & \multicolumn{3}{c}{ Cumulative multivariate statistics } & \multicolumn{3}{c}{ Increment } \\
\cline { 2 - 6 } Step & Parameter & Chi-square & $d f$ & Chi-square & $d f$ \\
\cline { 2 - 6 } 1 & 57 respect, F2 & 16.87 & 1 & 16.87 & 282 \\
2 & 10 interest, F2 & 24.22 & 2 & 7.34 & 281 \\
3 & 05 share, F2 & 30.73 & 3 & 6.52 & 280
\end{tabular}

Note. Abbreviations: CFI = Comparative Fit Index, SRMR = Standardized Root Mean-Square Residual, RMSEA = Root Mean Square Error of Approximation, and 90\% CI = 90\% Confidence Interval of RMSEA. An asterisk next to an "F" ( $\left.{ }^{*} \mathrm{~F}\right)$ indicates that the LM test was taken into account to improve fitting of the model. Absence of the asterisk indicates that it was not. Confirmatory factor analysis run by EQS (Bentler, 2006). 
Table 2 shows the results of fit indices for three models. The first, Model A (MMA), tests the fit of a unidimensional, one-factor scale. Two methods of estimation were chosen, maximum likelihood and robust. Indices were not satisfactory, with Comparative Fit Index, CFI $=.861$, and Root Mean Square Error of Approximation, RMSEA = .084 (method, robust), and Standardized Root MeanSquare Residual, SRMR $=.067$ (method, maximum likelihood). In reporting on model-fitting results, Byrne (2005) recommend that researchers specify the chi-square value followed by its degrees of freedom, and then report the goodness-of-fit statistics CFI, SRMR, and RMSEA together with its $90 \% \mathrm{CI}$ (Byrne, 2005). Indicators of a well-fitting model would be evidenced, says Byrne (2005), from a CFI value equal to or greater than .93, a SRMR value equal to or greater than .08, and a RMSEA value of less than .05. However, Browne and Cudeck asserts that a value of .05 or less of the RMSEA would indicate close fit, but they are ". . . also of the opinion that a value of about 0.08 or less for the RMSEA would indicate a reasonable error of approximation" (1993, p. 144).

We believe that these considerations about fit indices are enough for establishing a subjective judgment about how well our "final" proposed Measurement Model C (MMC) performs in the test of fitting to the validating subsample data. This is shown in Figure 3, which depicts MMC run by EQS (Bentler, 2006). With RMSEA at .056, and remaining indices presenting reasonable results, we conclude that the fitting indices turn out as favorable overall evidence to the theoretical model under discussion.

Now let us return to Table 2 and comment on its item $\mathrm{C}$, the multivariate Lagrange Multiplier test for adding parameters. In running Measurement Model B (MMB), we asked for specification search for Model B fit improvement. EQS delivered chi-square values indicate that item 14 tension should also be included in both factors F1 and F2. If so, there would be a chi-square drop of 103.77, representing the main source for improving model fit. Since it also coincides to being more meaningful according to our theoretical proposition, it was done when setting-up Measurement Model C. After the first, the next step that improves fit the most is to make indicator 16 feelings cross-load on both factors, with a 92.53 drop in chi-square. And so forth, going from item 14 tension, with a 103.77 chi-square drop, all the way down to a chi-square drop of 20.58 for the 23 talk item.

These chi-square figures were repeated in Figure 2, on the right side, next to their respective indicators. Examining the chi-square statistics magnitudes produced by the multivariate Lagrange Multiplier (LM) test for adding parameters by simultaneous process in the specification search presented in Table 2 (part C), we can see that the order from highest to lowest there corresponds to the order observed in the Component 2 loadings in the rightmost column at Table 1, as well as in the vertical column at the right side of Figure 1. These chi-square values are also reproduced in the right vertical side of Figure 2. Following the order of the values there, we see that they converge to the center as they diminish in value.

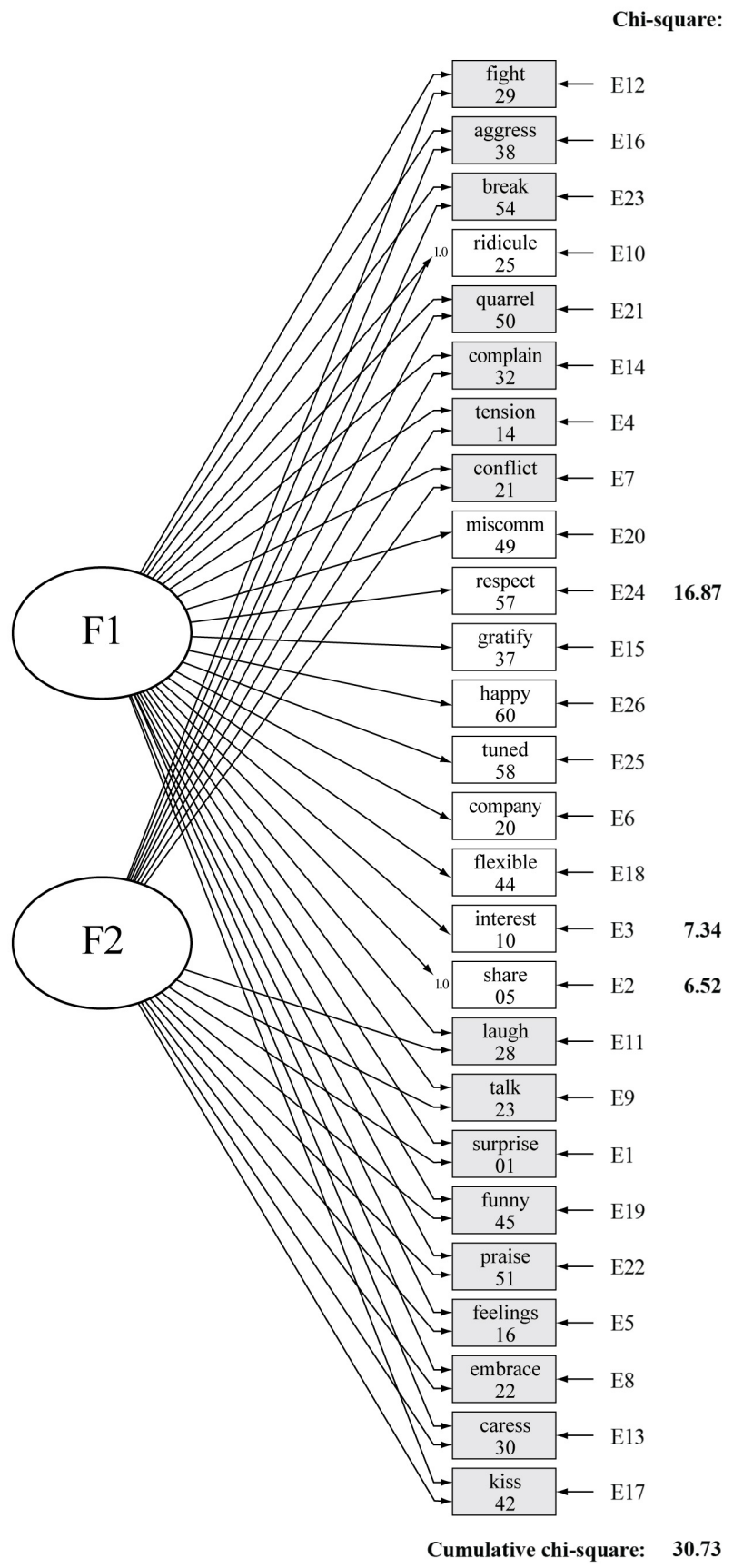

Figure 3. Confirmatory Factor Analysis (CFA) Measurement Model C

Note. Confirmatory factor analysis Model C run by EQS (Bentler, 2006) on validating subsample $(N=762)$. Comparative Fit Index, CFI $=.947$. Root Mean Square Error of Approximation, RMSEA $=.057 .90 \%$ Confidence Interval of RMSEA, CI $[.053, .060]$. Method $=$ robust. When first run on the calibrating subsample $(N=767)$ : $\mathrm{CFI}=942$. Root Mean Square Error of Approximation, RMSEA $=.056 .90 \%$ Confidence Interval of RMSEA, CI [.052, .060]. Method = robust. Measurement indicator weights fixed at 1.0 by EQS: share 05 $(1 \mathrm{~F} 1+\mathrm{E} 11)$ and ridicule $25(1 \mathrm{~F} 2+\mathrm{F} 1+\mathrm{E} 10)$. 
We can see, then, that the order of decreasing chi-square values of the LM test actually converge to positions at the center of the listing of loadings, where there is a reversal - of loading magnitude and direction, as well as of item semantic similarity. The reversing property of the nonorientable Möbius strip becomes a functional analogue as far as it models that empirical reversal. Hence, in addition to model fit per se, the breaking down of the multivariate LM test into a series of incremental univariate tests, a method "unique to EQS" (Bentler, 2006, p. 162 ), made it possible not only to test for Guttman's law of neighboring, but also to propose the Möbius strip for modeling our kind of data. But why, theoretically, specific response covariances compelled specific items to be neighbors in loading magnitude?

The items relating to affect are most responsible for the effect we have been discussing. Let us consider kiss, caress, and embrace as indicators of "love", and consider fight, aggress, and break as indicators of "hate". According to Freud (1915/1999a), the transformation of an instinct in its material contrary (die Verwandlung eines Triebes in sein (materielles) Gegenteil) is only observed in one instance (wird nur in einem Falle beobachtet) the transposition of love into hate (bei der Umsetzung von Liebe in Hass). Content reversal (inhaltliche Verkehrung) one finds in the unique case (findet sich in dem einen Falle) of the transformation of love into hate (der Verwandlung des Liebens in ein Hassen). Thus indicators of positive and negative affect, taken eihter as contraries or as opposing poles in the same continuum, may find a promising theoretical niche to be studied in future.

\section{Conclusion}

We conclude that our previously stated objective, to establish an instrument that is sensible enough to detect meaningful signs of how subjects are recollecting their parents' marital relations, was achieved. In the research setting, these signs are useful to identify how perception of parents as a couple influences how sons and daughters currently conceive the marital link in their lives. Moreover, they may be also useful in the clinical endeavor of helping people to better cope with their psychic inheritance. Components and factors are now meaningfully interpretable, and component scores can identify which people most contribute to which factor. This is one of our research prospects.

The kind of data generated by the Perception of Parents as a Couple measurement model have distinguishing characteristics. These characteristics would not be detected had we taken for granted the exploratory factor analysis orthogonal rotation result, which actually achieved simple structure, albeit meaningless to our theoretical underlying assumptions. For there is no simple way for people to cope with their psychic inheritance. A person memory, when recollecting data on parents, may well leave the explicit memory domain, and enter into the implicit memory realm. We propose the word "explicit" to name the role items play in the first factor or component, and the word "implicit" to name the role the same items play in the second factor. For decades now there have been studies on implicit memory, with extension to the explicit-implicit distinction into the domains of perception, learning, and thought. According to Kihlstrom (2008), this literature describes the cognitive unconscious (Kihlstrom, 1987, 1999). Further research may well contrast to the cognitive unconscious theoretical orientation, and the generational psychic transmission concepts of intersubjectivity and unconscious alliances (Kaës, 1993/2003, 2007, 2009). In so doing, we could explore which theoretical standpoint better explain our results bearing on the question of how people covariation in answers to items related to affect can play two different roles in the same instrument.

\section{References}

Bauman, Z. (2003). Liquid love: On the frailty of human bonds. Cambridge, UK: Polity Press.

Bentler, P. M. (2006). EQS 6 Structural Equations Program Manual. Encino, CA: Multivariate Software.

Browne, M. W., \& Cudeck, R. (1993). Alternative ways of assessing model fit. In K. A. Bollen \& J. S. Long (Eds.), Testing structural equation models (pp. 136-192). Newbury Park, CA: Sage.

Byrne, B. M. (2005). Factor analytic models: Viewing the structure of an assessment instrument from three perspectives. Journal of Personality Assessment, 85, 17-32.

Enriques, C. R., Féres-Carneiro, T., \& Magalhães, A. S. (2006). Trabalho e família: O prolongamento da convivência familiar em questão. Paidéia, 16, 327-336.

Féres-Carneiro, T., Seixas, A., \& Ziviani, C. (2006). Conyugalidad de los padres y proyectos de vida de los hijos frente al matrimonio [Sons and daughters' plans of marriage and their parent's marital relationship]. Cultura y Educación, 18, 95108.

Fowers, B. J., \& Olson, D. H. (1989). ENRICH Marital Inventory: A discriminant validity and cross-validity assessment. Journal of Marital and Family Therapy, 15, 65-79.

Freud, S. (1999a). Triebe und Triebschicksale [Instinct and their vicissitudes]. In S. Freud, Gesammelte Werke X [Complete Works X] (pp. 210-232). Frankfurt, Germany: Fischer. (Original work published 1915)

Freud, S. (1999b). Zur Einführung des Narzissmus [Introduction to narcissism]. In S. Freud, Gesammelte Werke X [Complete Works X] (pp. 137-170). Frankfurt, Germany: Fischer. (Original work published 1914)

Graham, J. W. (2009). Missing data analysis: Making it work in the real world. Annual Review of Psychology, 60, 549576.

Guttman, L. (1955). A new approach to factor analysis: The radex. In P. Lazarsfeld (Ed.), Mathematical thinking in the social sciences (2nd Rev. Ed., pp. 258-348). Glencoe, IL: The Free Press. (Original work published 1954)

Hair, J. F., Jr., Black, W. C., Babin, B. J., Anderson, R. E., \& Tatham, R. L. (2006). Multivariate data analysis ( $6^{\text {th }}$ ed.). Upper Saddle River, NJ: Pearson Prentice-Hall. 
Jolliffe, I. T. (2004). Principal component analysis ( $2^{\text {nd }}$ ed.). New York: Springer.

Jöreskog, K. G. (1993). Testing structural equation models. In K. A. Bollen \& J. S. Long (Eds.), Testing structural equation models (pp. 294-316). Newbury Park, CA: Sage.

Jöreskog, K. G. (2007). Factor analysis and its extensions. In R. Cudeck \& R. C. MacCallum (Eds.), Factor analysis at 100: Historical developments and future directions (pp. 4777). Mahwah, NJ: Lawrence Erlbaum.

Kaës, R. (2003). Introduction au concept de transmission psychique dans la pensée de Freud [Introduction to the concept of psychic transmission in the thinking of Freud]. In R. Kaës, H. Faimberg, M. Enriquez, \& J.-J. Baranes (Eds.), Transmission de la vie psychique entre generations [Transmission of psychic life between generations] (pp. 17-58). Paris: Dunod. (Original work published 1993)

Kaës, R. (2007). Linking, alliances, and shared space: Groups and the psychoanalyst (A. Weller, Trans.). London: The International Psychoanalytical Association.

Kaës, R. (2009). Les alliances inconscientes [Unconcious alliances]. Paris: Dunod.

Kihlstrom, J. F. (1987). The cognitive unconscious. Science, 237, 1445-1452.

Kihlstrom, J. F. (1999). Conscious versus unconscious cognition. In R. J. Sternberg (Ed.), The nature of cognition (pp. 173-203). Cambridge, MA: The MIT Press.

Kihlstrom, J. F. (2008). The psychological unconscious. In O. P. John, R. W. Robins, \& L. A. Pervin (Eds.), Handbook of personality: Theory and research (pp. 583-602). New York: Guilford Press.

Melchert, T. P. (1998). A review of instruments for assessing family history. Clinical Psychology Review, 18, 163-187.

Melchert, T. P., \& Sayger, T. V. (1998). The development of an instrument for measuring memories of family of origin characteristics. Educational and Psychological Measurement, 58, 99-118.

Möbius, A. F. (1886). Zur Theorie der Polyëder und der Elementarverwandtschaft. In F. Klein (Ed.), Gesammelte Werke: Vol. 2 (pp. 519-559). Leipzig, Germany: Verlag von S. Hirzel.

Olson, D. H., \& Fowers, B. J. (1993). Five types of marriage: An empirical typology based on ENRICH. The Family Journal, 3, 196-207.

Plutchik, R. (1997). The circumplex as a general model of the structure of emotions and personality. In R. Plutchick \& H. R. Conte (Eds.), Circumplex models of personality and emotions (pp. 103-132). Washington, DC: American Psychological Association.

Ramos, E. (2003). Âge et places dans la cohabitation intergénérationnelle [Age and places in the intergenerational cohabitation]. Agora, 33, 98-108.

Raykov, T., \& Marcoulides, G. A. (2008). An introduction to applied multivariate analysis. New York: Routledge.

Tabachnick, B. G., \& Fidell, L. S. (2007). Using multivariate statistics. Boston, MA: Allyn \& Bacon. 
